\title{
Use of Injection Drugs and Any Form of Methamphetamine in the Portland, OR Metro Area as a Driver of an HIV Time-Space Cluster: Clackamas, Multnomah, and Washington Counties, 2018-2020
}

\author{
Jaime Walters ${ }^{1}$ (D) $\cdot$ Lea Busy $^{2} \cdot$ Christopher Hamel $^{3} \cdot$ Kelsi Junge $^{3} \cdot$ Timothy Menza $^{2} \cdot$ Jaxon Mitchell $^{3} \cdot$ Taylor Pinsent $^{3}$. \\ Kim Toevs ${ }^{3}$. Jennifer Vines ${ }^{4}$
}

Accepted: 23 October 2021 / Published online: 10 November 2021

(c) The Author(s), under exclusive licence to Springer Science+Business Media, LLC, part of Springer Nature 2021

\begin{abstract}
We describe the response to detection of a time-space cluster of new HIV infection in the Portland, OR metro area among people who inject drugs (PWID) and/or people who use any form of methamphetamine. This time-space cluster took place in a region with a syndemic of homelessness and drug use. The investigation included new HIV diagnoses in 2018, 2019, and 2020 in Clackamas, Multnomah, and Washington Counties. Public health response included activating incident command, development and implementation of an enhanced interview tool, outreach testing, and stakeholder engagement. We identified 396 new cases of HIV infection, 116 (29\%) of which met the cluster definition. Most cluster cases had no molecular relationships to previous cases. Persons responding to the enhanced interview tool reported behaviors associated with HIV acquisition. Field outreach testing did not identify any new HIV cases but did identify hepatitis C and syphilis infections. We show the importance of a robust public health response to a time-space cluster of new HIV infections in an urban area.
\end{abstract}

Keywords Surveillance $\cdot$ Epidemiology $\cdot$ HIV cluster investigation · Injection drug use $\cdot$ Non-injection methamphetamine

\section{Introduction}

HIV incidence among people who inject drugs (PWID) in the United States is increasing [1,2]. In Oregon, new cases of HIV have declined, largely due to decreases in HIV diagnoses among men who have sex with men (MSM). However, the proportion of new infections attributable to injection drug use (IDU) has increased, especially in the Portland metro area (PMA) [3, 4]. Between 2015 and 2019, the

Jaime Walters

jaime.walters@multco.us

1 Multnomah County Health Department, Epidemiology, Analytics, and Evaluation, Community Epidemiology Services, 619 NW 6th Avenue, 6th Floor, Portland, OR 97209, USA

2 Public Health Division, HIV/STD/TB Program, Oregon Health Authority, Portland, OR, USA

3 Public Health Division, Multnomah County Health Department, Communicable Disease/STD/HIV, Portland, OR, USA

4 Health Officer Division, Multnomah County Health Department, Portland, OR, USA proportion of new infections attributable to IDU increased in females (from 31 to 58\%) and IDU in MSM and other men by (from 15 to 27\%) (unpublished data, Multnomah County Health Department, 2021). Although the rate of new HIV infections in the United States among PWID remained stable from 2008 to 2013 [5], data suggests the opioid epidemic has fueled outbreaks and clusters of HIV infections [2]. This study details the response to a time-space cluster of HIV in the PMA in people who inject drugs and use any form of methamphetamine [6]. The successful response to this time-space cluster involved an interdisciplinary team of county, state, harm reduction, and community partners.

Like many places across the United States, Oregon saw an increase in opioid use disorder, as well as opioid overdose hospitalizations and deaths, in the early 2000s. Between 2000 and 2015, the opioid mortality rate tripled in Oregon [7]. Oregon has also seen an increase in accidental methamphetamine/psychostimulant deaths as well as from other synthetic opioids such as fentanyl [8]. In the Portland Metro Area, the rate of fatal opioid overdoses declined between 2011 and 2015, but started increasing again in 2015 [9]. The number of deaths attributed to fentanyl increased substantially between 2015 and 2019 (from 13 to 47 deaths) [9]. 
There have been HIV outbreaks and clusters among PWID reported in rural and urban settings over the last decade [2, 5, 10-14]. Factors identified as contributing to an outbreak in rural Indiana were lack of access to prevention services and opioid addiction treatment $[11,14]$. In larger urban settings like Seattle, WA, houselessness and injection drug use were associated with an outbreak of HIV in 2018 [13], highlighting vulnerabilities in this marginalized community. Additionally, Seattle also experienced an increased number of new HIV infections among heterosexuals who inject methamphetamine [12]. An outbreak in northeastern Massachusetts [10] in 2016-2017 showed an increase in HIV among PWID after sustained decreases in the years prior in an area with robust harm reduction services. Recently, research linked an HIV outbreak in West Virginia to the 2018 cancellation of a needle exchange program $[15,16]$. Expansion of drug treatments, such as medication-assisted treatment (MAT), are an essential component to reducing the spread of HIV and other infectious diseases, such as hepatitis C $[2,4,5,10,11,14]$.

Rapid identification of outbreaks and clusters of HIV is a key component of the U.S. Ending the HIV Epidemic Initiative. This is especially important given that persons unaware of their infection or not engaged in care transmit as many as $92 \%$ of new cases [17]. Identification of transmission clusters (i.e., time-space and molecular clusters) is a critical step to help focus prevention tools where they are needed the most [18]. Molecular methods (i.e., genetic sequencing) are routinely done as part of clinical care, and these data can provide information about transmission relationships and identify clusters that might not be identified through more traditional methods (e.g., partner services) [19-21].

We discuss the detection of a time-space cluster of new HIV cases in Multnomah County among PWID and MSMPWID, with common exposures and contacts in the greater Portland metro area, just after identification of a molecular cluster of related cases months earlier, in the context of a steady decline in HIV cases over the prior 5 years. Response to this cluster included use of the incident command structure, development of an enhanced investigation interview tool, and community and stakeholder outreach and engagement across multiple modalities of the HIV surveillance and care continuum.

\section{Methods}

\section{Cluster and Response Timeline}

In late 2018, four new cases of HIV from Multnomah County were linked by molecular analysis with a fifth case (the threshold for investigation) identified in early 2019 (Fig. 1). All cases reported use of methamphetamine (both injection and non-injection), and OHA and MCHD were anticipating an increase in cases among these users. In addition to routine molecular analysis, OHA runs time-space cluster analysis on statewide HIV case data. In May 2019, OHA identified a significantly higher than expected number of people with new HIV infection among people who inject drugs (PWID) and MSM-PWID in Multnomah County.

The results of the molecular analysis in combination with the time-space cluster analysis triggered MCHD to activate its incident command system (ICS), to manage investigation as well as prevention opportunities. The response team was interdisciplinary and included county health officers and public health leadership, state partners (OHA's medical director and HIV surveillance staff), local harm reduction and disease investigation staff, clinicians, community testing staff, epidemiologists, and communications staff. In June 2019, MCHD issued a broad clinician alert and held a press conference to increase information about the increase in HIV. In August 2019, MCHD convened a community partner roundtable, to share information and brainstorm strategies in care access, viral transmission, harm reduction, addictions treatment, and other key areas. By the end of 2019, MCHD had created, tested, and deployed an enhanced interview (EI) to identify overlapping risk factors for both HIV and syphilis cases. In January 2020, MCHD began the use of a rapid (finger stick) HIV antibody test as well as dried blood spot (DBS) antibody testing for hepatitis $\mathrm{C}(\mathrm{HCV})$ and syphilis and antibody/antigen testing for HIV. In mid-March 2020, at the start of the COVID-19 "stay home, save lives" restrictions, MCHD began increasing the numbers of syringes available in health kits; on March 27, 2020, a full needs based distribution policy began (i.e., no 1:1 requirement for exchange). MCHD discontinued outreach testing during this time; we restarted in January 2021 (Fig. 1).

\section{Cluster Definition}

We defined a cluster case as a laboratory-confirmed HIV infection diagnosed in a resident of the PMA (Clackamas, Multnomah, or Washington County, OR) in calendar year 2018,2019 , or 2020 , who used any form of methamphetamine and/or reported injecting drugs or was a contact/sex partner of a case. For the purposes of this investigation timeline, we describe new HIV cases diagnosed through December 2020. Cluster cases were identified as such by an outbreak ID entered by OHA HIV surveillance staff.

\section{Molecular Definition}

Commercial laboratories report HIV genetic sequences to $\mathrm{OHA}$ as part of testing for routine clinical care. OHA analyzed sequences with HIV-TRACE software, using pairwise 


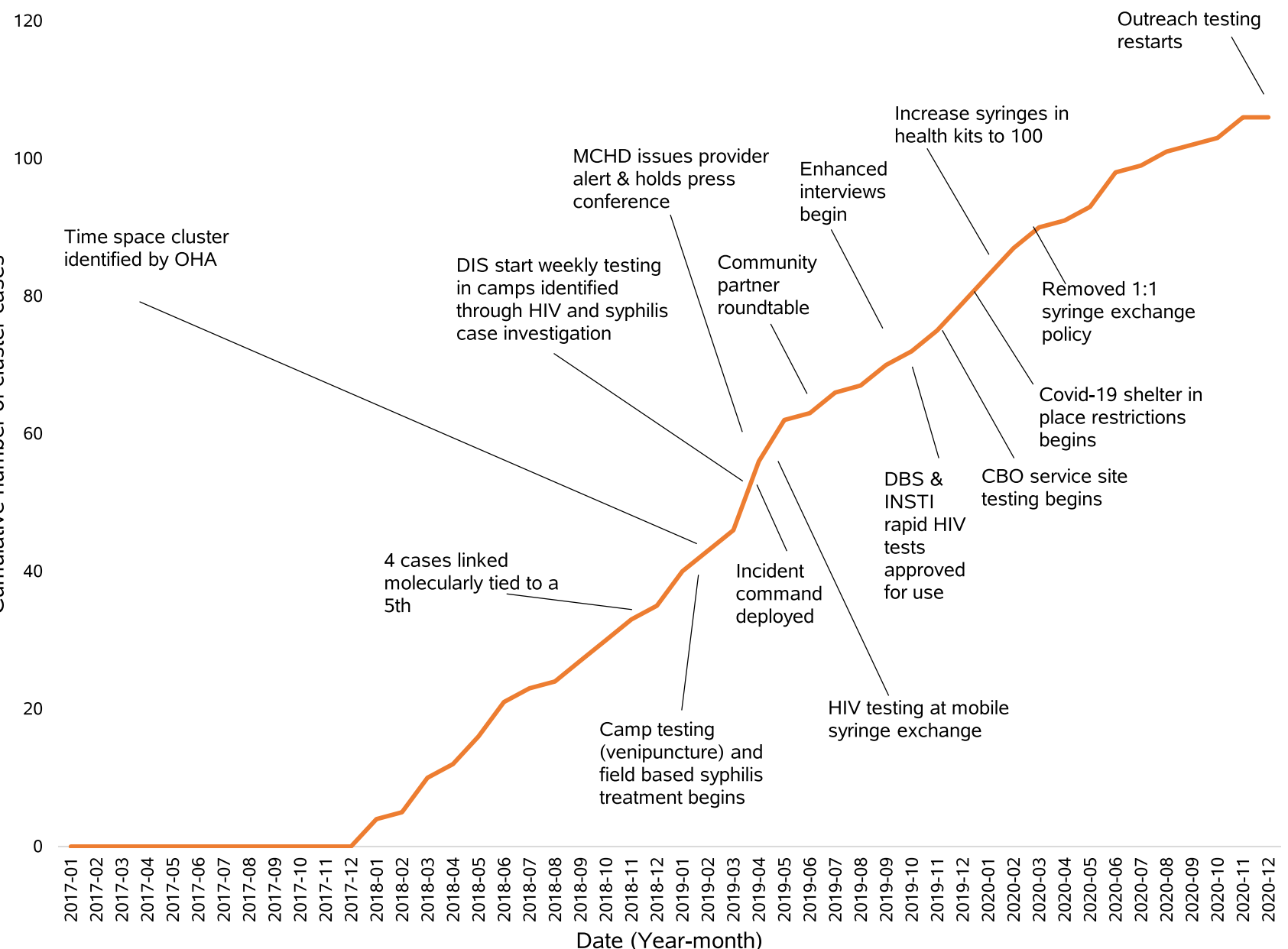

Fig. 1 Cumulative HIV cluster cases and timeline of investigation and response activities, Portland, OR metro area, 2018-2020

genetic distances of $1.5 \%(\leq 0.015$ substitutions per site $)$ and $0.5 \%(\leq 0.0005$ substitutions per site) [18].

\section{Epidemiology, Partner Services, and Enhanced Interview}

MCHD collects demographic, risk factor, clinical, and other information on all persons diagnosed with HIV in our county; Washington and Clackamas Counties use the same data system (Oregon Public Health Epidemiologists' User System or ORPHEUS) and collect similar information. Lab tests, including viral load (VL) and CD4 count/percent, are reportable to the county health department [22]. Hepatitis $\mathrm{C}$ lab results are also reportable to the county health department; status was determined by a confirmed or presumptive case within 15 days of HIV diagnosis date [23]. Disease intervention specialists (DIS) conduct interviews including contact elicitation and partner services. DIS also apply a data to care strategy, conducting targeted outreach to residents living with HIV who have not had VL or CD4 labs reported in the past 13 months. All DIS receive training in motivational interviewing and integrate harm reduction outreach, including syringe and naloxone distribution, into their field services.

Routine risk factor questions collected in the ORPHEUS system are limited and did not meet the needs of this cluster investigation to understand social, sexual, and drug use behaviors among cluster members. Therefore, to identify overlapping risk factors possibly driving transmission, we created an enhanced interview (EI) tool that was distinct from the DIS case interview process. Any case of HIV was eligible for the EI, with cases meeting the cluster definition being the first priority. Due to the increase in syphilis in the same population, we expanded the eligibility for the EI to include syphilis cases. However, for this analysis, we focus on persons in the time-space cluster. We conducted interviews both in person as well as by phone, and offered a $\$ 50$ visa card as an incentive to complete the interview. We present results in five major themes: (1) housing, mobility, and criminal justice; (2) sexual risk and pre-exposure prophylaxis (PrEP); (3) substance use and medication-assisted treatment (MAT); (4) change in sex partners and substance 
use; and (5) sharing practices, needles, and injection practices. Due to the small sample size, only frequencies were calculated.

Demographic characteristics are presented as frequencies and percentages by cluster status, with differences between groups compared by Pearson $\chi^{2}$ or Fisher's exact tests when cell sizes were less than or equal to 5. Statistical significance was defined as $p \leq 0.05$. All analyses were conducted using SAS 9.4 (SAS Institute, Cary, NC).

\section{Field Based Testing}

Coordinated outreach testing for HIV and syphilis, as well as field based bicillin syphilis treatment, began in March 2019 at encampments identified through DIS case investigations. Testing at this time was limited to venipuncture, which presented multiple barriers to successful specimen collection in the field. We began use of dried blood spot (DBS) specimen collection in January 2020 for antibody testing for syphilis and HCV and antibody/antigen testing for HIV (Molecular Testing Labs, Vancouver, WA) and obtained a CLIA waiver for use of rapid finger stick HIV testing (BioLytical Labs, Vancouver, British Columbia) [24]. We also began offering these same tests at our mobile syringe service program (SSP).

In February and March 2020, outreach testing began at two additional local organizations offering services to persons struggling with homelessness and addiction. We had to discontinue all outreach testing shortly after due to COVID-19 "stay home, stay safe" recommendations. Testing resumed in January 2021 at the mobile SSP, February 2021 at the first local organization, and March 2021 at the second. We added a fourth outreach test site (a parking lot in the east side of Multnomah County) in April 2021, alongside an organization that offers weekly mobile shower services.

\section{Results}

\section{Epidemiology}

There were 396 new HIV cases identified during the time of our investigation, 116 (29\%) of which met our cluster definition. Most cluster cases were between 30 and 39 years of age, assigned male sex at birth, and non-Hispanic white (Table 1). HIV cases not part of the cluster were significantly more likely to be Hispanic, while cluster cases were significantly more likely to be assigned female sex at birth. Nearly two-thirds of cluster cases were diagnosed in Multnomah County and occurred in 2019. Although not significantly different, more noncluster cases reported taking PrEP $(\mathrm{n}=29 ; 10 \%)$ compared to cluster cases $(n=6 ; 5 \%)$. Cluster cases were more likely to be unstably housed at the time of diagnosis $(n=62 ; 53 \%)$ compared to noncluster cases $(n=120 ; 43 \%)$. Among 44 cases who reported use of non-injection methamphetamine, 19 (43\%) denied otherwise using injection drugs of any type (data not shown).

The most frequent mode of transmission for all cases was male to male sexual (MSM) contact $(n=251 ; 63 \%)$ (Table 2). Among cluster cases, IDU $(\mathrm{n}=40 ; 34 \%)$ or MSM + IDU $(n=49 ; 42 \%)$ were the most common modes. A smaller proportion of cluster cases were diagnosed with AIDS $(n=20 ; 17 \%)$ compared to noncluster cases $(n=66$; 24\%). When hepatitis C status could be determined, cluster cases were more likely to have a confirmed or presumptive case on or before their HIV diagnosis date $(n=21$; $17 \%)$ compared to non-cluster cases $(n=8 ; 3 \%)$. Cluster cases had a lower proportion of initial CD4 T-cell count of $<200$ cells $/ \mu \mathrm{L}(\mathrm{n}=16 ; 14 \%)$ compared to noncluster cases $(n=63 ; 22 \%)$. However, the proportion of cases with a recent viral load (within 12 months of analysis) indicating suppression $(<200$ copies $/ \mathrm{mL}$ ) was significantly lower in cluster cases $(n=73 ; 63 \%)$ compared to noncluster cases $(n=223 ; 80 \%)$. For all 396 cases in this analysis, the most frequently reported facility for HIV diagnosis was outpatient $(n=221 ; 56 \%)$ (Table 2$)$. However, cluster cases were much more likely to be diagnosed as an inpatient $(\mathrm{n}=18 ; 16 \%)$ compared to noncluster cases $(\mathrm{n}=29 ; 10 \%)$.

\section{Molecular Testing}

Of the 116 cluster cases identified, 88 (76\%) had molecular sequences reported to surveillance. Molecular sequence data identified only a few distantly related cases in the cluster, with the bulk of cases being singles (i.e., no molecular relationship to a previously reported HIV case in Oregon), or were in small groups of two to three cases (data not shown).

\section{Partner Services}

DIS conducted interviews for 338 cases (85\%); the proportion by year was stable. Cluster and noncluster cases were equally likely to be interviewed (241/280, $86 \%$ vs. $97 / 116$, $84 \%$ ). When contacts could be located, the contacts per case for cluster cases was 1.2 (117/97), and for noncluster cases was 0.7 (158/241) (data not shown).

Eighty-six of $116(74 \%)$ cluster cases had a viral load within 30 days of diagnosis date, compared to $230(82 \%)$ of noncluster cases; this difference was not significant. Ninety-five of $116(82 \%)$ cluster cases had a viral load within 60 days of diagnosis date, compared to $252(90 \%)$ of noncluster cases; this difference was significant $(\mathrm{p}<0.05)$. 
Table 1 Demographic characteristics of reported HIV cases by cluster status, Portland, OR metro area, 2018-2020

\begin{tabular}{|c|c|c|c|c|}
\hline & No. $(\%)$ & Cluster case, no. (\%) & $\begin{array}{l}\text { Noncluster } \\
\text { case, no. (\%) }\end{array}$ & Chi-square (p-value) \\
\hline Total & 396 & $116(29)$ & $280(71)$ & \\
\hline Age at diagnosis (years) & & & & $1.7163(0.6333)$ \\
\hline $17-29$ & $141(36)$ & $37(32)$ & $104(37)$ & \\
\hline $30-39$ & $145(37)$ & $48(41)$ & $97(35)$ & \\
\hline $40-49$ & $64(16)$ & $18(15)$ & $46(16)$ & \\
\hline$\geq 50$ & $46(12)$ & $13(11)$ & $33(12)$ & \\
\hline Sex at birth ${ }^{\mathrm{a}}$ & & & & $10.5450(0.0012)$ \\
\hline Male & $360(91)$ & $97(84)$ & $263(94)$ & \\
\hline Female & $36(9)$ & $19(16)$ & $17(6)$ & \\
\hline County of HIV diagnosis & & & & $3.9105(0.1415)$ \\
\hline Clackamas & $50(13)$ & $18(16)$ & $32(11)$ & \\
\hline Multnomah & $250(63)$ & $77(66)$ & $173(62)$ & \\
\hline Washington & $96(24)$ & $21(18)$ & $75(27)$ & \\
\hline Year of HIV diagnosis & & & & $5.4960(0.0641)$ \\
\hline 2018 & $152(38)$ & $35(30)$ & $117(42)$ & \\
\hline 2019 & $138(35)$ & $49(42)$ & $89(32)$ & \\
\hline 2020 & $106(27)$ & $32(28)$ & $74(26)$ & \\
\hline Race/ethnicity & & & & $10.1211(0.0176)$ \\
\hline White & $223(57)$ & $79(68)$ & $144(51)$ & \\
\hline Hispanic & $97(25)$ & $18(16)$ & $79(28)$ & \\
\hline Black/Af Amer & $40(10)$ & $9(8)$ & $31(11)$ & \\
\hline All other & $33(8)$ & $8(7)$ & $25(9)$ & \\
\hline Ever used PrEP & & & & $1.8164(0.1777)$ \\
\hline Yes & $35(11)$ & $6(5)$ & $29(10)$ & \\
\hline No & $284(89)$ & 79 (95) & $205(90)$ & \\
\hline \multicolumn{5}{|l|}{ Housing status $^{\mathrm{a}}$} \\
\hline Unstably housed & $182(46)$ & $62(53)$ & $120(43)$ & \\
\hline Stably housed & $214(54)$ & $54(47)$ & $160(57)$ & \\
\hline
\end{tabular}

${ }^{a}$ Significant difference in characteristic between cluster and noncluster HIV cases, Chi-square, $\mathrm{p} \leq 0.05$

${ }^{\mathrm{b}}$ Excludes missing or unknown values

\section{Enhanced Interviews}

DIS interviewed 22 HIV cases in the time-space cluster using the EI tool between November 20, 2019 and April 30, 2020; complete EI data are available upon request. Nineteen $(86 \%)$ of respondents were male, with a median age of 34.5 years. Fourteen $(64 \%)$ identified as white, and five (23\%) identified as Hispanic. Sixteen (73\%) affirmed injection drug use, with a median age at first injection of 27 years.

\section{Theme 1: Housing, Mobility, and Criminal Justice}

Nine $(41 \%)$ reported an unstable housing situation at the time of diagnosis, with 5 (23\%) saying they moved 2-10 times in the year before diagnosis. Emergency department (ED) visits were frequent; one third of respondents who visited an ED reported 2 to 5 ED visits in the 12 months prior to diagnosis. Four total respondents indicated an incarceration in the 12 months prior to diagnosis; 2 (50\%) had one visit, while the other half had $2-5$ visits.

\section{Theme 2: Sexual Risk and PrEP}

Chem sex (the use of drugs to enhance sexual arousal, pleasure, or stamina) $(\mathrm{n}=18 ; 82 \%)$ and sex without a condom $(\mathrm{n}=15 ; 68 \%)$ was commonly reported in this cohort. More than one third of survey respondents reported receiving something of value for sex; when given a list of options for the exchange, the most frequent items of value reported were drugs $(75 \%)$, money $(63 \%)$, or a place to stay/pornorgraphy/ shower/phone charger (38\%). When asked about PrEP, 15 (68\%) respondents had heard of PrEP, and 5 (33\%) of those had ever used it. Although a number of respondents declined answering why they could not get PrEP, the most common barriers reported were related to insurance and cost. 
Table 2 Clinical characteristics of reported HIV cases by cluster status, Portland, OR metro area, 2018-2020

\begin{tabular}{|c|c|c|c|c|}
\hline & No. $(\%)$ & $\begin{array}{l}\text { Cluster } \\
\text { case, No. } \\
(\%)\end{array}$ & $\begin{array}{l}\text { Noncluster } \\
\text { case, No. (\%) }\end{array}$ & Chi-square (p-value) \\
\hline Total & 396 & $116(29)$ & $280(71)$ & \\
\hline Exposure category & & & & $\mathrm{n} / \mathrm{a}^{\mathrm{a}}$ \\
\hline MSM only & $251(63)$ & $21(18)$ & $230(82)$ & \\
\hline IDU only & $42(11)$ & $40(34)$ & $2(1)$ & \\
\hline MSM + IDU & $50(13)$ & $49(42)$ & $1(<1)$ & \\
\hline $\begin{array}{l}\text { Heterosexual contact with a person living } \\
\text { with HIV/AIDS but no known risk }\end{array}$ & $12(3)$ & $0(0)$ & $12(4)$ & \\
\hline Heterosexual contact with MSM & $6(2)$ & $1(1)$ & $5(2)$ & \\
\hline Heterosexual contact with IDU & $6(2)$ & $3(3)$ & $3(1)$ & \\
\hline Adult with undetermined infection mode & $29(7)$ & $2(2)$ & $27(10)$ & \\
\hline Stage at diagnosis & & & & $1.9331(0.1644)$ \\
\hline HIV & $310(78)$ & $96(83)$ & $214(76)$ & \\
\hline AIDS & $86(22)$ & $20(17)$ & $66(24)$ & \\
\hline \multicolumn{5}{|l|}{ Hepatitis C status ${ }^{\mathrm{b}}$} \\
\hline Unknown & $359(91)$ & $90(77)$ & $269(96)$ & $\mathrm{n} / \mathrm{a}(0.6720)^{\mathrm{e}}$ \\
\hline Prior or concurrent with HIV Infection & $29(7)$ & $21(17)$ & $8(3)$ & \\
\hline After HIV infection & $8(2)$ & $5(4)$ & $3(1)$ & \\
\hline Earliest CD4+T-cell (cells/ $\mu \mathrm{L})$ & & & & $5.2829(0.0713)$ \\
\hline$<200$ & $79(20)$ & $16(14)$ & $63(22)$ & \\
\hline$\geq 200$ & $296(74)$ & $91(78)$ & $205(73)$ & \\
\hline No data & $21(5)$ & $9(8)$ & $12(4)$ & \\
\hline Result of most recent viral load ${ }^{c, d}$ & & & & $15.6121(0.0004)$ \\
\hline$<200$ copies/mL & $296(74)$ & $73(63)$ & $223(80)$ & \\
\hline$\geq 200$ copies $/ \mathrm{mL}$ & $18(5)$ & $11(9)$ & $7(3)$ & \\
\hline No data & $82(21)$ & $32(28)$ & $50(18)$ & \\
\hline Category of diagnosing provider ${ }^{\mathrm{c}}$ & & & & $13.7189(0.0082)$ \\
\hline Outpatient & $221(56)$ & $51(44)$ & $170(61)$ & \\
\hline STD clinic or community testing site & $67(17)$ & $22(19)$ & $45(16)$ & \\
\hline Inpatient & $47(12)$ & $18(16)$ & $29(10)$ & \\
\hline Other & $11(3)$ & $7(6)$ & $4(1)$ & \\
\hline Missing or unknown & $50(13)$ & $18(16)$ & $32(11)$ & \\
\hline
\end{tabular}

${ }^{\mathrm{a}}$ Test not performed (exposure category was part of original case definition)

${ }^{\mathrm{b}}$ Confirmed or presumptive case within 15 days or earlier from HIV diagnosis (prior or concurrent)

${ }^{\mathrm{c}}$ Significant difference in characteristic between cluster and noncluster HIV cases, Chi-square, $\mathrm{p} \leq 0.05$

${ }^{\mathrm{d}}$ Within 12 months. Reasons for no data could include death, moving out of jurisdiction, or out of care

${ }^{\mathrm{e}}$ Fisher's exact test

\section{Theme 3: Substance Use and Medication Assisted Treatment (MAT)}

Seventeen $(77 \%)$ respondents indicated that they use methamphetamine and that methamphetamine is their drug of choice; of these persons, five $(29 \%)$ had been in drug treatment in the year before their HIV diagnosis. Two (9\%) respondents indicated that they use heroin and that it is their drug of choice; none of these respondents had been in drug treatment in the year prior to HIV diagnosis. Seven (32\%) reported mixing methamphetamine and heroin. Of these seven, $4(57 \%)$ had been in a drug treatment program. For respondents who had participated in any sort of treatment, $4(57 \%)$ said they tried to get MAT but could not due to lack of stable housing.

\section{Theme 4: Change in Sex Partners and Substance Use}

More than half of respondents said they changed the area of town that they were spending time in or using drugs in the past year and more than $75 \%$ indicated that they changed sexual partners. Over half of respondents indicated a change in the amount of drug used in the 12 months prior to HIV 
diagnosis, and nearly $62 \%$ indicated a change in the frequency of injection.

\section{Theme 5: Sharing and Injection Practices}

Among PWID, 6 (40\%) report injecting three or more times per day; 3 (20\%) report using a needle after someone else injected with it. Around a third of PWID report using syringe service programs (SSP). Of these SSP users, the majority also get other supplies while there (e.g., cookers, cotton, water). For the PWID who do not utilize SSP, they indicated getting supplies from other places, such as drug stores, or another person using syringe service programs. They listed a variety of barriers to using syringe services programs; common themes were fear of stigma, law enforcement, location, and hours of operations.

\section{DIS Field Based Testing}

Table 3 lists results from field based testing. Overall, the highest proportion of reactivity was seen with the hepatitis $\mathrm{C}$ testing done on dried blood spot cards $(n=32 ; 27 \%)$ followed by syphilis $(\mathrm{n}=11 ; 9 \%)$. For HIV, no fingerstick antibody tests were reactive, and one antibody/antigen test was reactive. Further investigation of this reactive test revealed this person as a known previous positive case.

\section{Discussion}

This time-space cluster of new HIV infections occurred primarily in PWID as well as in persons using non-injection methamphetamine in the urban Portland, OR metro area.
This area has a high rate of opioid use disorder, and has seen increasing deaths from opioids, especially fentanyl [7, $25,26]$. Sexual and behavioral practices that promote HIV transmission (condomless anal sex, chem sex, multiple injections per day, using used needles and other shared equipment) were frequently reported. Only about half of all cases disclosed sexual or close contacts with DIS, and molecular methods later identified mainly singlets or groups of two to three cases. Further, cluster cases were less likely to be engaged in care. These findings have implications for the Ending the HIV Epidemic initiative, given the increasing rise of HIV cases in other urban area with adequate or robust harm reduction services, which could suggest changes in sexual and drug networks rather than a new introduction of HIV [27].

Very few cases in the time-space cluster had a history of ever taking PrEP. Results from the enhanced survey showed that more than two-thirds of respondents had heard of PrEP, but only around one-third had actually used PrEP in the year before their HIV diagnosis. CDC recommends daily PrEP for prevention of HIV infection in high risk populations, including PWID, where it can reduce transmission by $74 \%$ [28, 29]. Data from the National Behavioral Surveillance (NHBS) system (which includes the PMA) showed an extremely low use of PrEP among PWID in the 2018 cycle $(\sim 3 \%)$ [30]. Other studies have shown barriers to PrEP uptake among persons with the greatest access (i.e., urban MSM) related to cost and insurance; more data is needed to inform how PrEP could be made more to PWID [31]. Persons participating in our enhanced survey, while not representative of all new HIV cases among PWID, listed similar reasons ("No insurance;" "didn't want a daily pill;" I was too late").
Table 3 Types and results of field based testing, Portland, OR metro area, 2020-2021

\begin{tabular}{llll}
\hline & Total & 2020 & 2021 \\
\hline $\begin{array}{l}\text { HIV antibody (fingerstick) } \\
\text { Reactive }\end{array}$ & $0(0)$ & $0(0)$ & $0(0)$ \\
$\quad$ Not reactive & $76(100)$ & $18(100)$ & $58(100)$ \\
HIV antibody/antigen (DBS ${ }^{\mathrm{a}}$ ) & & & \\
Reactive & $1(1)$ & $1(2)$ & $0(0)$ \\
Not reactive & $124(99)$ & $42(98)$ & $82(100)$ \\
Hepatitis C antibody (DBS) & & & $19(24)$ \\
Reactive & $32(27)$ & $13(34)$ & $52(66)$ \\
Not reactive & $77(66)$ & $25(66)$ & $8(10)$ \\
Preliminary reactive (unable to be confirmed) & $8(7)$ & $0(0)$ & $8(10)$ \\
Syphilis antibody EIA (DBS) & & & $69(85)$ \\
Reactive & $11(9)$ & $3(7)$ & $4(5)$ \\
Not reactive & $109(88)$ & $40(93)$ & $0(0)$ \\
Preliminary reactive (unable to be confirmed) & $4(3)$ &
\end{tabular}

On or before May 1, 2021

${ }^{\text {a}}$ Dried blood spot 
Results from the enhanced interviews indicate multiple interactions with the healthcare system in the year before HIV diagnosis. Emergency departments often see PWID for healthcare for complications of drug use, and these visits may be missed opportunities for HIV screening [32]. Analysis of local NHBS data for the 2018 PWID cycle demonstrated that $80 \%$ of PWID had any healthcare visit in the previous year, and $86 \%$ reported being insured, mainly through Medicaid. Sixty percent had a skin or soft tissue infection [30]. Hospitalizations for IDU-related serious bacterial infections increased substantially in Oregon between 2008 and 2018; these visits are costly and could be missed opportunities to initiate conversations about harm reduction strategies [33].

Universal screening for HIV in high-risk areas, as recommended by the Centers for Disease Control and Prevention, has shown some successes, but there remain a number of logistical hurdles, including cost, low acceptance, and lack of cultural competency $[34,35]$. Opt out testing in MiamiDade County, Florida, raised the number of HIV tests performed in one emergency department from 800 tests prior to this change to more than 20,000 [36]. In the PMA, ED HIV screening could be one component of a larger strategy, with resources to local community and public health harm reduction services. In March 2021, an adult ED of an academic medical center in Portland, OR, began triage-based universal HIV testing (personal communication, Julia Lager-Mesulam, March 15, 2021). Evaluation of this program should provide insight and opportunities for future policy goals.

Results from the enhanced interviews among new HIV cases showed that one third had participated in a drug treatment program in the year before their HIV diagnosis, but a low proportion tried medication-assisted treatment (MAT). Since our cluster cases were predominantly PWID but included many methamphetamine users, it follows that we might observe a low proportion trying MAT, which has historically been specific for opioid-use disorder. However, newer evidence shows a small but nonzero treatment effect for MAT for methamphetamine use disorder compared to placebo, which could have an important effect on increasing treatment options [37]. A comprehensive model that involves behavioral therapy, individual counseling, drug testing, and incentives has been shown to be effective for treating methamphetamine addiction [38].

Nearly one-third of respondents to the enhanced survey use both methamphetamine and heroin, either together or separately. Results from Multnomah County's own survey of SSP users has shown an increase in the proportion of persons using both methamphetamine and heroin (unpublished data, Multnomah County Health Department). Seattle has also demonstrated increased use of goofball (heroin + methamphetamine simultaneously). Presumably, this increase has increased the mixing of sexual and needle sharing networks, although self-reported prevalence of HIV was lower among goofball users compared to primary methamphetamine users [39]. Meacham et al. demonstrated an association among PWID who co-injected heroin and methamphetamine and HIV drug injection behaviors as well as sexual risk behavior (sex exchange and drug use before sex) compared to PWID who did not co-inject. However, in the multivariate analysis the sexual risk behaviors were not significantly associated with co-injection [40]. The authors hypothesize that the independent association between HIV drug injection behaviors (sharing needles, cookers, equipment) overshadowed the smaller association of sexual behavior. Given the small number of enhanced interviews, we are unable to fully evaluate the link between co-injection and HIV transmission in our cohort.

Field based testing was low yield in identifying new diagnoses of HIV. Only one person had a reactive test, and further investigation revealed this person was a previously known positive who was homeless and out of care. However, by the time MCHD was ready to deploy the dried blood spot collection system as well as the finger stick rapid HIV test, the count of new cases of HIV had already begun to decline. Further, all outreach testing was paused in March 2020 due to the shelter in place orders instituted by Oregon's governor in response to the COVID-19 pandemic. Partner services with contact elicitation was able to identify more new cases of HIV than field testing, although 50\% of cases (cluster and noncluster) revealed no contacts (data not shown). Prior analysis of other Oregon transmission clusters, especially MSM or MSM + PWID, have shown molecular links between cases, even when partners were not named. The lack of molecular links in the current context may indicate a significant underdiagnosis of HIV among PWID, gaps in genotyping data, or acquisition of HIV outside of our state. Partner services, especially in the context of increased use of mobile technology, is and continues to be a vital part of reducing the transmission of HIV [41].

Community partnerships were vital to this response, especially given existing barriers for PWID in our community (e.g., stigma, regional housing crisis). MCHD has longstanding relationships with two community-based organizations (CBOs); both of these organizations are funded subcontractors to provide HIV testing, and one provides SSP and works with PWID directly. Staff from both CBOs supported response activities by engaging their trusted client base, integrating messaging about the situation during service delivery, and helping to amplify public health talking points throughout their networks.

Limitations to this investigation and response include the small number of respondents to the enhanced survey. Further, the survey was designed before implementation of the needs based syringe exchange policy, so we were unable to link this policy with subsequent reduction in 
HIV transmission behaviors. Results are not applicable to all cases of HIV, and not all respondents were PWID. HIV cases declined from 2019 to 2020, which may be explained by something other than our response efforts. The COVID19 pandemic interrupted many HIV testing and other inperson health services. Although many agencies pivoted to telehealth or in-person physically distant services, HIV testing rates declined compared to the previous year. How much effect this could have had on the HIV time-space cluster is unclear. Further, due to competing resource constraints, MCHD incorporated response work into routine operations, affecting resources and staff available to respond to clusters and outbreaks of HIV. Given that COVID-19 likely will be an issue in the near and distant future, our response shows that a flexible, community-partner driven response with data-informed harm reduction strategies is imperative.

\section{Conclusions}

A time-space cluster of new HIV infections occurred in the PMA despite the presence of robust harm reduction services. A comprehensive approach is needed to address rising HIV rates and outbreaks, including but not limited to robust and data informed syringe service policies, including the following:

(1) Access to MAT for opioid use disorder;

(2) Access to treatment for methamphetamine use disorder;

(3) Addressing homelessness and other factors that make it difficult for persons diagnosed with HIV to stay in treatment;

(4) Enlisting ED and hospital providers in screening for $\mathrm{HIV}$; and

(5) Strong community partnerships, including local and state public health partners as well as trusted community based organizations.

Acknowledgements The authors would like to acknowledge the disease intervention specialists conducting the case investigations and enhanced interviews in Clackamas, Multnomah, and Washington Counties, as well Jeff Capizzi and Amy Zlot at Oregon Health Authority, and Carrie Shuler at Washington County Public Health.

Author Contributions All authors contributed to the investigation and response activities outlined in this article. Jaime Walters wrote the first draft of the article and all authors commented on previous versions of the manuscript. All authors read and approved the final manuscript.

Funding NA.

Data Availability NA.

Code Availability NA.

\section{Declarations}

Conflict of interest The authors declare that they have no conflict of interest.

Ethical Approval This study was considered public health practice and review by an Institutional Review Board was not sought.

Consent to Participate NA.

Consent for Publication NA.

\section{References}

1. Centers for Disease Control and Prevention. Managing HIV and hepatitis C outbreaks among people who inject drugs-A guide for state and local health departments. 2018. https://www.cdc.gov/ hiv/pdf/programresources/guidance/cluster-outbreak/cdc-hiv-hcvpwid-guide.pdf. Accessed 3 Mar 2021.

2. Hodder SL, Feinberg J, Strathdee SA, et al. The opioid crisis and HIV in the USA: deadly synergies. Lancet. 2021;397(10279):1139-50.

3. Oregon Health Authority, Public Health Division. Epidemiologic profile of HIV infection in Oregon. 2018. https://sharedsystems. dhsoha.state.or.us/DHSForms/Served/le9998.pdf. Accessed 3 Mar 2021.

4. Oregon Health Authority, Public Health Division. Injection Drug Use and HIV in Oregon. 2018. https://sharedsystems.dhsoha.state. or.us/DHSForms/Served/le9988.pdf. Accessed 3 Mar 2021.

5. Mitsch AJ, Hall HI, Babu AS. Trends in HIV infection among persons who inject drugs: United States and Puerto Rico, 2008-2013. Am J Public Health. 2016;106(12):2194-201.

6. Multnomah County. Health officials alert public to increase in HIV infections among people who use drugs. 2019. https://www. multco.us/multnomah-county/news/health-officials-alert-publicincrease-hiv-infections-among-people-who-use. Accessed 10 Aug 2021.

7. Oregon Health Authority, Public Health Division. Opioid Overdose in Oregon: Report to the Legislature. 2018. https://www. oregon.gov/oha/PH/PREVENTIONWELLNESS/SUBSTANCEU SE/OPIOIDS/Documents/OHA2479.pdf. Accessed 3 Mar 2021.

8. Hedberg K, Bui L, Livingston C, Shields LM, Van Otterloo J. Integrating public health and health care strategies to address the opioid epidemic: the Oregon Health Authority's Opioid Initiative. J Public Health Manag Pract. 2019;25(3):214-20.

9. CDC WONDER. Multiple Cause of Death 1999-2019. Centers for Disease Control and Prevention, National Center for Health Statistics. 2020. https://wonder.cdc.gov. Accessed 2 Mar 2021.

10. Alpren C, Dawson EL, John B, et al. Opioid use fueling HIV transmission in an urban setting: an outbreak of HIV infection among people who inject drugs-Massachusetts, 2015-2018. Am J Public Health. 2020;110(1):37-44.

11. Conrad C, Bradley HM, Broz D, et al. Community outbreak of HIV infection linked to injection drug use of oxymorphone-Indiana, 2015. MMWR Morb Mortal Wkly Rep. 2015;64(16):443-4.

12. Glick SN, Burt R, Kummer K, et al. Increasing methamphetamine injection among non-MSM who inject drugs in King County, Washington. Drug Alcohol Depend. 2018;182:86-92.

13. Golden MR, Lechtenberg R, Glick SN. Outbreak of human immunodeficiency virus infection among heterosexual persons who are living homeless and inject drugs - Seattle, Washington, 2018. MMWR Morb Mortal Wkly Rep. 2019;68(15):344-9. 
14. Peters PJ, Pontones P, Hoover KW, et al. HIV infection linked to injection use of oxymorphone in Indiana, 2014-2015. N Engl J Med. 2016;375(3):229-39.

15. Atkins A, McClung RP, Kilkenny M, et al. Notes from the field: outbreak of human immunodeficiency virus infection among persons who inject drugs - Cabell County, West Virginia, 2018-2019. MMWR Morb Mortal Wkly Rep. 2020;69(16):499-500.

16. Kerr T, Small W, Buchner C, et al. Syringe sharing and HIV incidence among injection drug users and increased access to sterile syringes. Am J Public Health. 2010;100(8):1449-53.

17. Fauci AS, Redfield R, Sigounas G, Weahkee M, Giroir B. Ending the HIV epidemic: a plan for the United States. JAMA. 2019;321(9):844-5.

18. Centers for Disease Control and Prevention. Detecting and responding to HIV Transmission clusters. A guide for health departments. June 2018. https://www.cdc.gov/hiv/pdf/funding/ announcements/ps18-1802/CDC-HIV-PS18-1802-AttachmentEDetecting-Investigating-and-Responding-to-HIV-TransmissionClusters.pdf. Accessed 2 Mar 2021.

19. Dennis AM, Pasquale DK, Billock R, et al. Integration of contact tracing and phylogenetics in an investigation of acute HIV infection. Sex Transm Dis. 2018;45(4):222-8.

20. Oster AM, France AM, Mermin J. Molecular epidemiology and the transformation of HIV prevention. JAMA. 2018;319(16):1657-8.

21. Oster AM, France AM, Panneer N, et al. Identifying clusters of recent and rapid HIV transmission through analysis of molecular surveillance data. J Acquir Immune Defic Syndr. 2018;79(5):543-50.

22. Oregon Health Authority, Public Health Division. Oregon Disease Investigative Guidelines. HIV Infection and AIDS. 2012. https://www.oregon.gov/oha/PH/DISEASESCONDITIONS/ COMMUNICABLEDISEASE/REPORTINGCOMMUNICABL EDISEASE/REPORTINGGUIDELINES/Documents/hiv_aids. pdf. Accessed 12 Feb 2021.

23. Oregon Health Authority, Public Health Division. Oregon Disease Investigative Guidelines. Hepatitis C. 2020. https://www.oregon. gov/oha/PH/DISEASESCONDITIONS/COMMUNICABLEDIS EASE/REPORTINGCOMMUNICABLEDISEASE/REPOR TINGGUIDELINES/Documents/hepc.pdf. Accessed 13 Aug 2021.

24. INSTI HIV-1/HIV-2 antibody test kit [package insert]. Richmond, BC, Canada: bioLytical Laboratories. 2019.

25. Oregon Health Authority, Public Health Division. A Quick Introduction to Medications For Opioid Use Disorder. 2019. https://www.oregon.gov/oha/PH/PREVENTIONWELLNESS/ SUBSTANCEUSE/OPIOIDS/Documents/MOUD-factsheet.pdf. Accessed 8 Apr 2021.

26. Oregon Health Authority. OHA sees $70 \%$ increase in Oregon drug overdose deaths during April, May. 2020. https://www.oregon. gov/oha/ERD/Pages/OHA-sees-70-percent-increase-in-Oregonopioid-deaths-during-April-May.aspx. Accessed 8 Apr 2021.

27. Lyss SB, Buchacz K, McClung RP, Asher A, Oster AM. Responding to outbreaks of human immunodeficiency virus among persons who inject drugs-United States, 2016-2019: perspectives on recent experience and lessons learned. J Infect Dis. 2020;222(Suppl 5):S239-49.

28. National Institute of Allergy and Infectious Diseases. Pre-exposure Prophylaxis (PrEP) to Reduce HIV Risk. 2020. https://www. niaid.nih.gov/diseases-conditions/pre-exposure-prophylaxis-prep. Accessed 9 Apr 2021.
29. Centers for Disease Control and Prevention. Pre-exposure Prophylaxis (PrEP) Care System. 2020. https://www.cdc.gov/hiv/effec tiveinterventions/prevent/prep/index.html. Accessed 9 Apr 2021.

30. Lipira L. and Bhattara A. National HIV Behavioral Surveillance, IDU5 2018. Chime In updates: Key findings from cycle 5, people who inject drugs in the Portland MSA. 2019: Portland, OR.

31. Oregon Health Authority, Public Health Division. Experiences of PrEP Use among People Recently Diagnosed with HIV in Oregon, 2016-2019. 2020. https://www.oregon.gov/oha/PH/DISEA SESCONDITIONS/HIVSTDVIRALHEPATITIS/HIVPREVENT ION/Documents/Experiences_of_PrEP_Use_Among_People_ Recently_Diagnosed_with_HIV.pdf. Accessed 9 Apr 2021.

32. Furukawa NW, Blau EF, Reau Z, et al. Missed opportunities for human immunodeficiency virus (HIV) testing during injection drug use-related healthcare encounters among a cohort of persons who inject drugs with HIV diagnosed during an outbreakCincinnati/Northern Kentucky, 2017-2018. Clin Infect Dis. 2020;72(11):1961-7.

33. Capizzi J, Leahy J, Wheelock H, et al. Population-based trends in hospitalizations due to injection drug use-related serious bacterial infections, Oregon, 2008 to 2018. PLoS ONE. 2020;15(11):e0242165.

34. Branson BM, Handsfield HH, Lampe MA, et al. Revised recommendations for HIV testing of adults, adolescents, and pregnant women in health-care settings. MMWR Recomm Rep. 2006;55:1-17.

35. Escudero DJ, Bahamon M, Panakos P, et al. How to best conduct universal HIV screening in emergency departments is far from settled. J Am Coll Emerg Phys Open. 2021;2(1):e12352.

36. Escudero DJ, Bennett B, Suarez S, et al. Progress and challenges in "getting to zero" new HIV infections in Miami, Florida. J Int Assoc Provid AIDS Care. 2019;18:2325958219852122.

37. Trivedi MH, Walker R, Ling W, Dela Cruz A, Sharma G, Carmody T, Ghitza UE, Wahle A, Kim M, Shores-Wilson K, Sparenborg S, Coffin P, Schmitz J, Wiest K, Bart G, Sonne SC, Wakhlu S, Rush AJ, Nunes EV, Shoptaw S. Bupropion and naltrexone in methamphetamine use disorder. N Engl J Med. 2021;384(2):140-53.

38. National Institute of Drug Abuse, National Institutes of Health, U.S. Department of Health and Human Services. October 2019. Methamphetamine Research Report. https://www.drugabuse.gov/ download/37620/methamphetamine-research-report.pdf?v=f6a96 a8721a56a0f765889a3d3e678c7. Accessed 9 Apr 2021.

39. Glick SN, Klein KS, Tinsley J, Golden MR. Increasing heroin-methamphetamine (goofball) use and related morbidity among seattle area people who inject drugs. Am J Addict. 2021;30(2):183-91.

40. Meacham MC, Strathdee SA, Rangel G, et al. Prevalence and correlates of heroin-methamphetamine co-injection among persons who inject drugs in San Diego, California, and Tijuana, Baja California, Mexico. J Stud Alcohol Drugs. 2016;77(5):774-81.

41. Frieden TR, Foti KE, Mermin J. Applying public health principles to the HIV epidemic-how are we doing? N Engl J Med. 2015;373(23):2281-7.

Publisher's Note Springer Nature remains neutral with regard to jurisdictional claims in published maps and institutional affiliations. 